\title{
Preclinical activity of gefitinib in non-keratinizing nasopharyngeal carcinoma cell lines and biomarkers of response
}

\author{
Brigette B.Y. Ma • Vivian W.Y. Lui • Fan Fong Poon • \\ S.C. Cesar Wong • Ka Fai To • Elaine Wong • Honglin Chen • \\ Kwok Wai Lo • Qian Tao • Anthony T.C. Chan
}

Received: 10 August 2009 /Accepted: 28 August 2009/Published online: 16 September 2009

(C) Springer Science + Business Media, LLC 2009

Summary This study evaluated the preclinical activity and
molecular predictors of response to gefitinib (Iressa ${ }^{\circledR}$, Astra
Zeneca Inc, UK) in nasopharyngeal carcinoma (NPC). The
activity of gefitinib was evaluated in four human NPC cell
lines-HK1, HONE-1, CNE2, C666-1. A representative
gefitinib-sensitive (HK1, IC $\mathrm{I}_{50}=250 \mathrm{nM}$ ) and gefitinib-

Brigette Ma \& Vivian Lui are joint 1st authors.

Electronic supplementary material The online version of this article (doi:10.1007/s10637-009-9316-7) contains supplementary material, which is available to authorized users.

B. B. Ma $\cdot$ V. W. Lui $\cdot$ F. F. Poon $\cdot$ S. C. Wong $\cdot$ E. Wong $\cdot$

K. W. Lo $\cdot$ Q. Tao $\cdot$ A. T. Chan

State Key Laboratory in Oncology in South China, Sir Y.K. Pao Centre for Cancer, Department of Clinical Oncology, Cancer Drug Testing Unit, Hong Kong Cancer Institute and Li Ka Shing Institute of Health Sciences, Chinese University of Hong Kong, Ngan Shing Street, Shatin,

New Territories, Hong Kong SAR, China

K. F. To

Department of Anatomical and Cellular Pathology,

State Key Laboratory in Oncology in South China,

Prince of Wales Hospital, The Chinese University of Hong Kong,

Ngan Shing Street, Shatin,

New Territories, Hong Kong SAR, China

H. Chen

Department of Microbiology, University of Hong Kong, University Pathology Building,

Queen Mary Hospital Compound, Pokfulam Road,

Pokfulam, Hong Kong SAR, China

B. B. Ma $(\bowtie)$

Department of Clinical Oncology, Basement,

LKS Specialist Clinic, Prince of Wales Hospital,

Shatin,

New Territories, Hong Kong SAR, China

e-mail: brigette@clo.cuhk.edu.hk resistant cell line (HONE-1, $\left.\mathrm{IC}_{50}>15 \mu \mathrm{M}\right)$ were selected and compared for expression of epidermal growth factor receptor (EGFR) and related ligands, and activation of downstream proteins. Gefitinib induced G1 cycle arrest, apoptosis and inhibited cell invasion more significantly in HK1 than HONE-1 cells. HK1 expressed higher levels of p-EGFR, lower p-AKT and phospho-signal transducer and activator of transcription 3 (p-STAT3) than other cell lines. $E G F R$ gene was found to be amplified in HK1. Gefitinib at $\mathrm{IC}_{50}$ concentrations significantly suppressed EGF-induced activation of p-EGFR, phospho-mitogen-activated protein kinase (p-MAPK) and p-STAT3, but p-AKT showed persistent activation in HK1 and HONE-1 cells. There was no difference in EGFR-ligand expression between the 4 NPC cell lines. In NPC samples derived from nonresponders to gefitinib, $50 \%$ and $60 \%$ showed cytoplasmic and nuclear pi-EGFR expression, respectively, and 33\% showed p-AKT expression. EGFR or KRAS mutations were not detected. This study suggests that most NPC cell lines are intrinsically resistant to gefitinib (except HK1 cells), and further studies are needed to confirm whether EGFR gene amplification and persistent AKT activation may influence response to gefitinib in NPC.

Keywords Head and neck cancer- Gefitinib .

Epidermal growth factor receptor

\section{Introduction}

Nasopharyngeal carcinoma (NPC) is endemic to China and the Southeast Asian region and areas like Hong Kong, where it reaches a peak incidence rate of around 20 per 100,000 person-years [1]. Our previous work supports 
epidermal growth factor receptor (EGFR) as a potential therapeutic target for NPC, as it is overexpressed in $80 \%$ of NPC and represents a negative prognostic factor [2]. Based on our work which has demonstrated the preclinical and clinical activity of the anti-EGFR antibody, cetuximab in NPC $[3,4]$ in NPC, we evaluated the EGFR tyrosine kinase inhibitor, gefitinib (ZD1839, Iressa ${ }^{\circledR}$, Astra Zeneca Inc, Macclesfield, UK) in a previously reported phase II trial in advanced NPC [5]. The objectives of the current study were to determine the preclinical activity and molecular predictors of response to gefitinib in NPC cell lines and in primary tumor biopsies obtained from our phase II study. These factors included the activation level of EGFR and its downstream signaling mediators (mitogen-activated protein kinase, MAPK; protein kinase B, AKT; signal transducer and activator of transcription 3, STAT3); expression level of EGFR-related ligands (epidermal growth factor, EGF; amphiregulin; heparin-binding EGF-like growth factor, HB-EGF; transforming growth factor alpha, TGF- $\alpha$ ); and the presence of any EGFR or KRAS mutations.

\section{Method and materials}

Cell culture

Analyses were carried in four human-derived NPC cell lines (CNE-2, C666-1, HONE-1 and HK1) and the normal nasopharyngeal epithelial cell line NP69 was used as a control.

\section{Reagents and antibodies}

Gefitinib was kindly provided by Astra Zeneca Inc (Macclesfield, UK). For in vitro experiments, the following antibodies were purchased from Cell Signaling Technology (Beverly, USA): anti-total EGFR, anti-phospho(p)-EGFR (Y1068), anti-total STAT3, anti-p-STAT3 (Tyr705); antitotal p44/42MAPK(Thr202/Tyr204), anti-p-p44/42MAPK (Thr202/Tyr204), AKT (\#9272S), anti-total AKT and p-AKT (Ser473) (\#9270S), antibody against cleaved poly(ADPribose) polymerase (PARP) proteins. Anti-beta-actin antibody was from Calbiochem, Merck (Gibbstown, USA). The following antibodies from Cell Signaling Technology (Beverly, USA) were used for immunohistochemistry: p-AKT (Ser473), anti-p-EGFR (Tyr 845), and p-EGFR (Tyr 992). MTT (3-(4,5dimethylthiazol-2-yl)-2,5-diphenyltetrazolium bromide) was from Invitrogen (USA) and recombinant human EGF was purchased from PeproTech (London, UK).

Cell viability assay

Cells were treated with increasing concentrations of gefitinib (from 0 to $100 \mu \mathrm{M}$ ) for up to 48 hours (h) and cytotoxicity was assessed by the MTT assay. Cells were cultured in 48well plates $(2,500-7,000$ cells/well) and then incubated with gefitinib at $24 \mathrm{~h}$ for 48 to $72 \mathrm{~h}$. DMSO was used as a blanking control. The drug concentration at which $50 \%$ of maximum growth inhibition was achieved was determined as the $\mathrm{IC}_{50}$ using the GraphPad PRISM software (ISS, San Diego, CA). All experiments were repeated in triplicates.

\section{Western blot and apoptosis}

Western Blot was used to detect the expression of total and phosphorylated levels of EGFR, MAPK, STAT3 and AKT in NPC cell lines, at basal condition and after treatment with gefitinib at or near $\mathrm{IC}_{50}$ concentration for $48 \mathrm{~h}$ under serum-starved and EGF-stimulated (20 ng/ml) conditions. Apoptosis was determined via detection of PARP cleavage proteins. Cell lysates were prepared as previously described [6] and $25 \mu \mathrm{g}$ of total protein was subjected to SDS-PAGE and immunoblotting with specific antibodies as listed above. Supersignal West Pico Chemiluminescence Western blotting detection reagents (ThermoFisher Scientific, USA) were used for signal detection by autoradiography.

\section{RNA extraction and RT-PCR}

The expression levels of EGFR-related ligands were determined by Reverse Transcription-Polymerase Chain Reaction (RT)-PCR. Total RNA was extracted from cell pellets using TriReagent (Molecular Research Center, USA) and treated with DNase by a TURBO DNA-free ${ }^{\mathrm{TM}}$ Kit (Ambion, USA). One $\mu \mathrm{g}$ of RNA was used for reverse transcription using the Go-Taq polymerase (Promega Co, USA) using GAPDH as control as previously described [7]. The primers and conditions are outlined in Table A of the section on Supplementary Material. RT-PCR products were analyzed on a $1.8 \%$ agarose gel.

\section{Cell cycle}

Cells were plated in $100-\mathrm{mm}^{2}$ Petri dishes $\left(3\right.$ to $\left.4 \times 10^{5}\right)$ and then treated with gefitinib for up to $24 \mathrm{~h}$. Cells were collected by trypsinization, fixed with $70 \%$ cold ethanol and stored at $-20^{\circ} \mathrm{C}$. DNA staining was performed with a solution containing RNase $(0.2 \mathrm{mg} / \mathrm{ml})$ and propidium iodide $(0.05 \mu \mathrm{g} / \mathrm{ml})$. Analysis was performed using a FACScan flow cytometer and data were processed with CELLQuest software (Becton Dickinson Co, USA).

Matrigel invasion assay

The cell invasion assay was performed using a Matrigel Invasion Chamber with a pore size of $8 \mu \mathrm{m}$ (Becton Dickinson Co, USA). Cells were seeded at a density of 
$25 \times 10^{4}$ cells per well (for HONE- 1 cells), or $7 \times 10^{4}$ cells per well (for HK1 cells) in serum-free medium. The cellcontaining chamber was immersed in a lower chamber containing either serum-free medium with or without gefitinib $(5 \mu \mathrm{M}, 15 \mu \mathrm{M})$, in the presence of EGF $(10 \mathrm{ng} / \mathrm{ml})$ or DMSO. After $24 \mathrm{~h}$, non-invaded cells retained in the upper chamber were removed and stained with $1 \%$ Toludine Blue O (Sigma, USA) in $1 \%$ Borax (USB, USA), and then counted under the microscope at 200 times magnification.

\section{EGFR gene amplification}

DNA copy number changes in NPC cell lines were analyzed by Agilent Human Genome CGH Microarray and scanned with a G2505B Agilent DNA microarray scanner as previously described [8]. Using the CGH Analytics Software 3.4, the array CGH data was analyzed and genomic profile of each sample was generated. All software and equipment used for microarray were from Aglient Technologies (USA). Z-score algorithm was applied for calculating the chromosomal aberration, and genes with $\log _{2}$ ratio greater than 1 were considered as amplified.

Immunohistochemistry

Paraffin-embedded samples of primary NPC biopsies were obtained before treatment from 9 participants (out of a total of 15) of a phase II trial of gefitinib in NPC [5]. This clinical protocol was approved by the Institutional Ethics Committee and all participants gave written informed consent. Tissue sections of $4 \mu \mathrm{m}$ thickness were immunostained using the Benchmark XT immunostainer and ultraView ${ }^{\mathrm{TM}}$ detection kit (Ventana Inc, USA). An immunostained sample of breast cancer was used as a positive control and the negative control was made by replacing the antibody with Tris buffered saline. Slides were evaluated under a light microscope at 200 times magnification by a pathologist (K.F.To). PhosphorylatedAKT (Ser473) expression was considered positive (1+) or negative, if nuclear staining was present or negative, respectively. The expression of pi-EGFR-Y845 was scored by estimating the proportion of tumor cells with positive nuclear staining (negative if none; $1+$, if less than or equal to $10 \% ; 2+$, if $10-50 \% ; 3+$, if over $50 \%$ ). The cytoplasmic expression of pi-EGFR-Tyr 992 was scored as previously described [2].

\section{Mutational analysis}

Paraffin-embedded NPC samples were deparafinized and DNA was isolated using QIAamp DNA Mini Kit (Qiagen $\mathrm{GmbH}$, Germany). Sections of $130 \mu \mathrm{m}$ thick were cut and dewaxed through suspension in $40 \mu \mathrm{L}$ of TK buffer. To inactivate the enzyme, samples were incubated at $55^{\circ} \mathrm{C}$ for 3 days and heated at $95^{\circ} \mathrm{C}$ for $10 \mathrm{~min}$. One $\mu \mathrm{L}$ of protein was used for PCR analysis, the amplicons were amplified
Fig. 1 a Effect of gefitinib (Iressa ${ }^{\circledR}, 15 \mu \mathrm{M}$ ) on apoptosis in HONE-1 cells as indicated by expression of cleaved PARP. b Effect of gefitinib (Iressa ${ }^{\circledR}$, $250 \mathrm{nM}$ ) on apoptosis in HK1 cells as indicated. c Gefitinib induced G1 Arrest in HONE-1 (left) and HK1 (right) cell lines following exposure for $24 \mathrm{~h}$ at IC50 concentrations by expression of cleaved PARP a

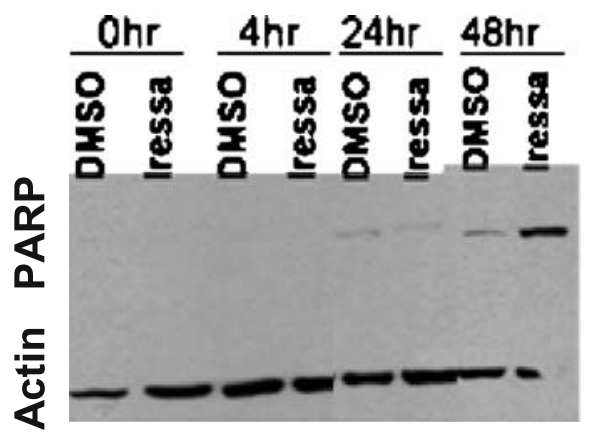

C

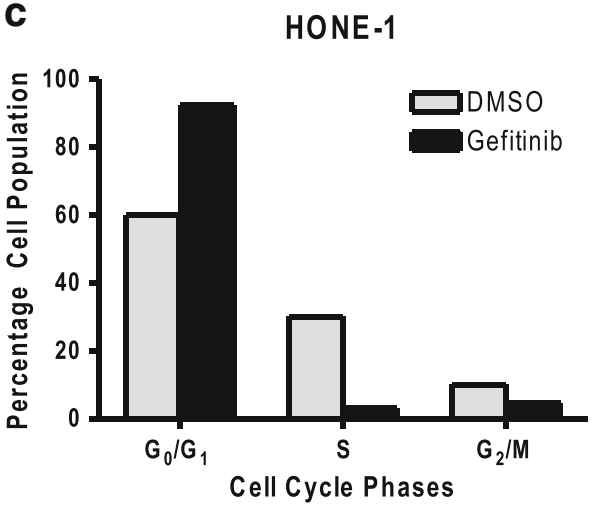

b

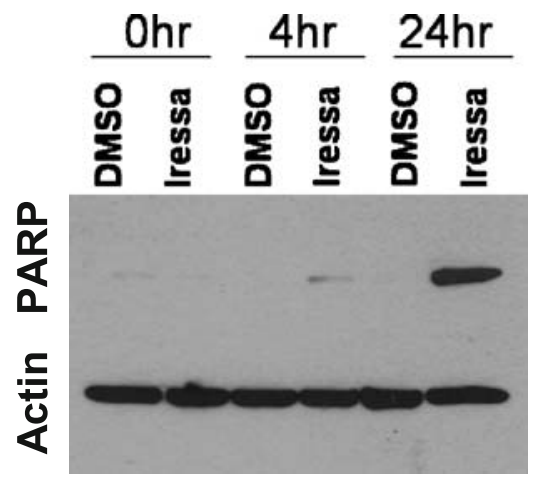

HK1

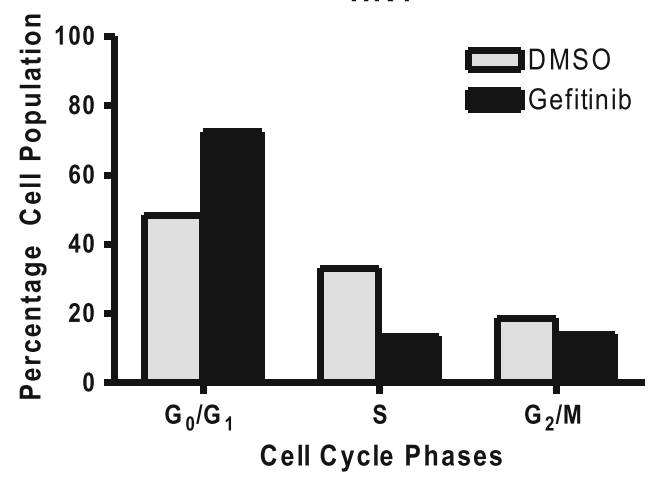


using AmpliTaq Gold polymerase (Applied Biosystems, USA) and purified using the High Pure PCR Purification Kit (Roche Diagnostics, USA). Sequencing was performed using the dRhodamine Terminator Cycle Sequencing Kit (PerkinElmer, USA) and the Applied Biosystems 310 Genetic Analyzer. The primers and PCR conditions are outlined in Table B of the section on Supplementary Material.

\section{Results}

Effect of gefitinib on growth, apoptosis, cell cycle progression and cell invasion

The $\mathrm{IC}_{50}$ value for gefitinib in $\mathrm{HK} 1$ cells $(250 \mathrm{nM})$ was the lowest compared with the other NPC cell lines of which the $\mathrm{IC}_{50}$ values ranged between $15-40 \mu \mathrm{M}$, while the $\mathrm{IC}_{50}$ for NP69 was $28.6 \mu \mathrm{M}$ (data was not shown). In order to elucidate the biological characteristics associated with sensitivity to gefitinib, HK1 and HONE-1 cell lines were chosen as a representative gefitinib-sensitive and gefitinib-resistant cell line, respectively, for all subsequent analyses described below.

When treated with gefitinib at $\mathrm{IC}_{50}$ concentrations, apoptosis was observed in both HK1 and HONE-1 cells after 24 to $48 \mathrm{~h}$ as evident by an increased expression of cleaved PARP (Fig. 1a and b). Exposure to gefitinib at similar concentrations also resulted in $\mathrm{G}_{1}$ cycle arrest (Fig. 1c), and inhibition of the invasive activity of HONE-1 and HK1 cells compared with control (Fig. 2).

Molecular profile of gefitinib-sensitive and gefitinib insensitive cell lines

At basal condition, the level of total and p-EGFR and pMAPK was higher in HK1 compared to HONE-1 cells (Fig. 3a). In contrast, the level of p-AKT and p-STAT3 were higher in HONE-1 compared with HK1 cells, while there were no significant differences in the levels of total AKT, STAT3 and MAPK expression. However, such differences were not observed under EGF-stimulated conditions (Fig. 3b). When HK1 and HONE-2 cells were treated with gefitinib at or near their respective $\mathrm{IC}_{50}$ concentrations, the level of p-MAPK and p-STAT3 were significantly reduced in both cell lines (Fig. 3c). Phosphorylated AKT expression was significantly reduced when both cell lines were treated with gefitinib well above the respective $\mathrm{IC}_{50}$ concentrations (Fig. 3b). The expression level of TGF- $\alpha$, EGF, HB-EGF, amphiregulin were compared in HK1 and HONE-1 cell lines. No difference was found in the ligand expression level of these cell lines (Fig. 3d). Furthermore, none of the cell lines harbored EGFR TK mutations (data not shown). In order to explain why HK1 cells expressed such high level of p-EGFR in the absence of EGFR activating
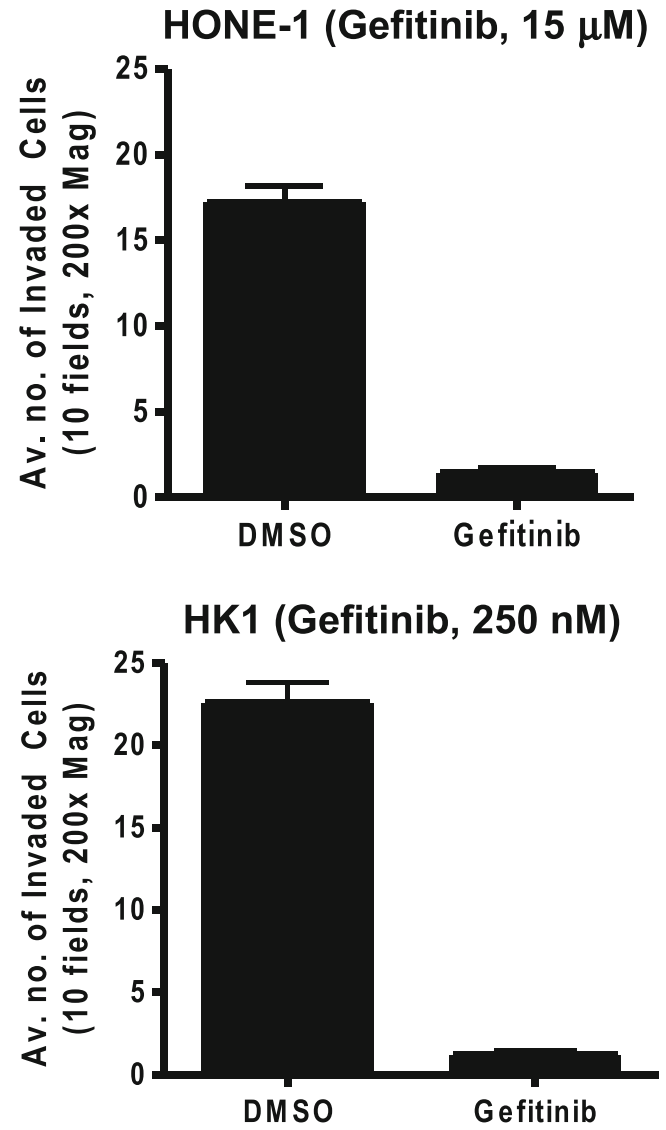

Fig. 2 Gefitinib (at $\mathrm{IC}_{50}$ concentration) inhibited NPC cell invasion through the Matrigel

mutations, HK1 cells were analyzed for gene amplification and a high level of EGFR amplification was found using aCGH microarray platform (Fig. 4). The threshold $\log _{2}$ ratio of this amplicon core was around 3.

Immunohistochemistry and EGFR mutation in tumor samples

Of the pre-treatment biopsies obtained from 9 patients, only 3 samples showed mild $(+1)$ p-AKT expression. Under half (4/9 samples) of the samples showed EGFR overexpression (cytoplasmic staining), while the 6 (out of 9) samples showed mild to moderate nuclear expression of EGFR (see Table 1 and Fig. 5). None of the tumors analyzed harbor $K R A S$ or EGFR mutations (data not shown). Since clinical response was not observed in the previously reported phase II study [5], correlation between immunohistochemical results and clinical response was not performed.

\section{Discussion}

In this study, gefitinib was found to inhibit cell growth and invasion, induce apoptosis and G1 cycle arrest in human 
a

\section{HK-1 CNE-2 C666.1 Hone1}

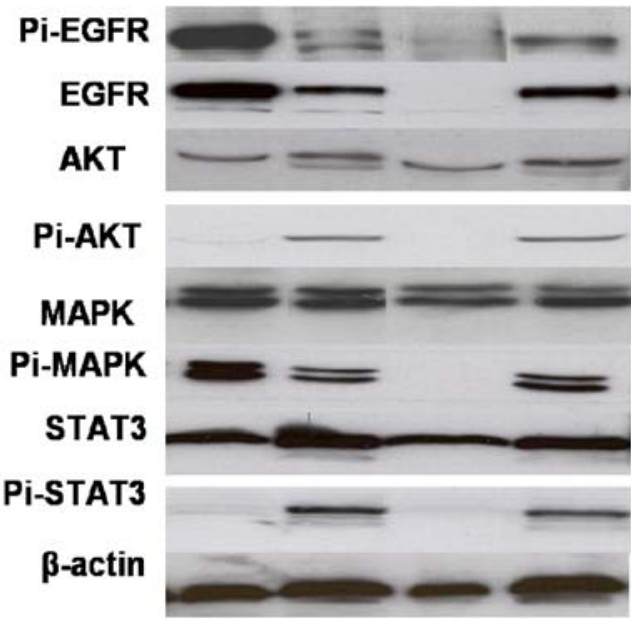

C
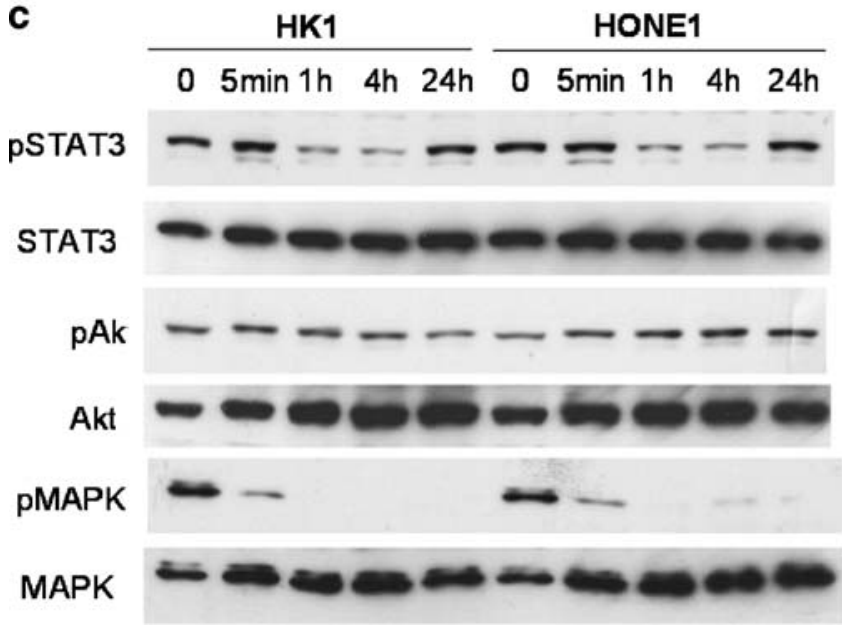

Fig. 3 a Basal expression of activated and total EGFR and its downstream mediators in NPC cell lines (serum-starved condition). b Expression of downstream mediators of EGFR in HK1 and HONE-1 at basal, serum-starved, EGF-stimulated (20 ng/ml) and above- $\mathrm{IC}_{50}$

NPC cell lines, as consistent with previous reports in other cancer types $[9,10]$. However, the relatively high concentrations required to achieve these effects suggested that most NPC cell lines are intrinsically resistant to gefitinib, with the exception of HK1. Furthermore, treatment with gefitinib at $\mathrm{IC}_{50}$ concentrations significantly inhibited EGFinduced phosphorylation of important downstream mediators of EGFR, namely, STAT3 and MAPK to a similar extent in both HK1 and HONE-1 cells, but AKT activation appeared to remain persistent in both cell lines at similar concentration. These results prompted the need to elucidate the molecular basis of these changes by evaluating the activation level of EGFR and its downstream signaling b

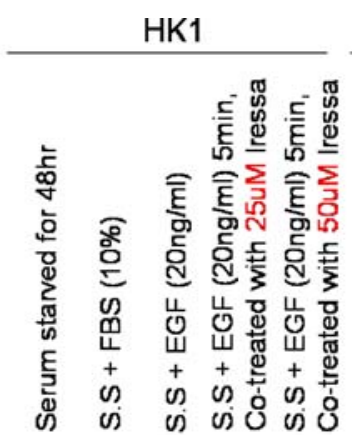

HONE-1

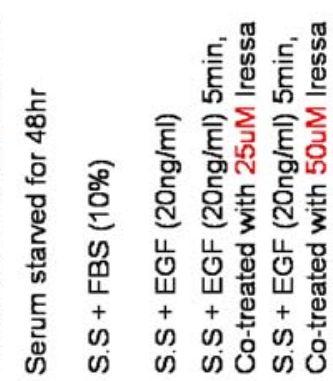

pSTAT3

Total STAT3

pAkt

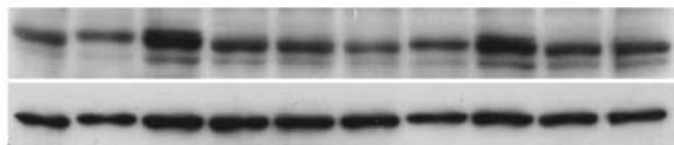

Total Akt

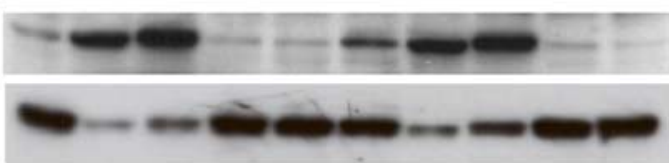

pMAPK

Total MAPK

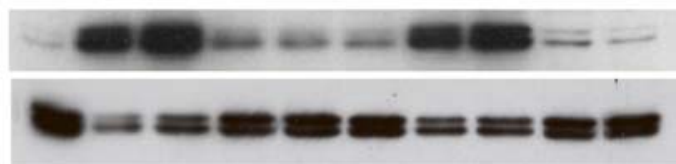

d

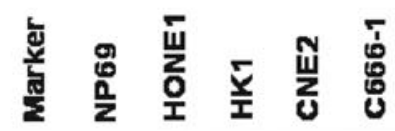

EGF

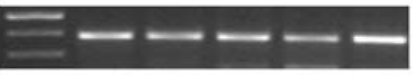

Amphiregulin

HB-EGF

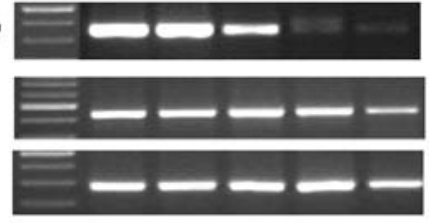

TGF- $\alpha$

GADPH

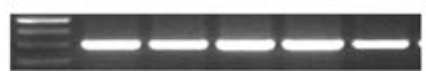

concentration of gefitinib (Iressa ${ }^{\circledR}$ ). c Expression of downstream mediators of EGFR in HK1 $(250 \mathrm{nM})$ and HONE-1 $(15 \mu \mathrm{M})$ at or near IC50 concentration of gefitinib. $\mathbf{d}$ Expression of EGFR ligands in NPC cell lines

mediators, ligand expression, presence of EGFR mutations and gene amplifications in NPC, by comparing these molecular profiles between a representative gefitinibsensitive (HK1) and a resistant cell line (HONE-1).

The 2 cell lines differed in the basal activation level of EGFR and downstream mediators, in that HK1 cells expressed a higher level of p-EGFR and p-MAPK, while HONE-1 expressed a higher level of p-AKT and p-STAT3. However, MAPK, AKT and STAT3 activation were similar in both cell lines under EGF-stimulated condition, suggesting that these signaling axes are inherently intact. Previous studies in other cancer types have associated resistance to gefitinib with increased level of MAPK (e.g. prostate 


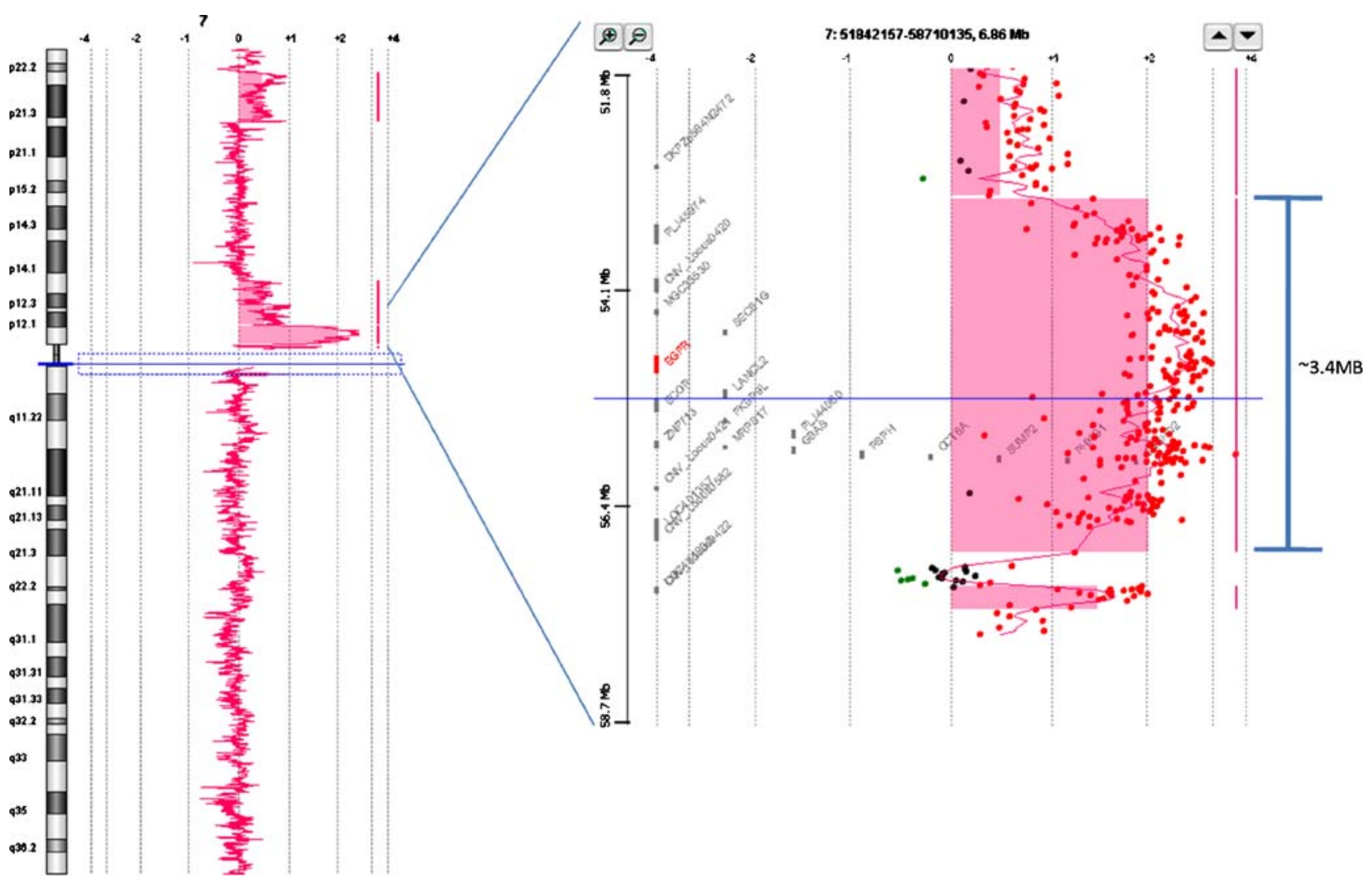

Fig. 4 High level of EGFR gene amplification was detected in HK1 by aCGH microarray. A high density oligonucleotide aCGH platform with 236,000 features with an average spatial resolution of $\sim 6.4 \mathrm{kB}$ was used. (Agilent's $244 \mathrm{~K}$ Human Genome CGH microarray)

cancer cells) [11] and AKT (e.g. in lung [12] and glioma cells [13]. As consistent with our study, increased STAT3 activation can be found in gefitinib-resistant glioma cells, despite the fact that STAT3 could be easily inhibited at low doses of gefitinib [13]. As in our NPC cell lines, higher concentrations of gefitinib was required to inhibit AKT and MAPK activation compared with EGFR in gefitinib- resistant glioma cells, suggesting that the AKT signaling maybe an escape mechanism for the inhibitory effect of gefitinib [13].

$E G F R$ was found to be amplified in the gefitinib-sensitive HK1 cell lines. Gain in gene copy number or EGFR gene amplification is a common event in NPC, and further validation is needed to elucidate whether EGFR amplifica-

Table 1 Immunohistochemical analysis of NPC samples

\begin{tabular}{|c|c|c|c|c|}
\hline Patient & Tissue type & pAKT-ser473 staining & EGFR-Tyr 992 (cytoplasmic) staining & EGFR-Tyr 845 (Nuclear) staining \\
\hline 1 & NP & Neg & Neg & $\mathrm{Neg}$ \\
\hline 2 & $\mathrm{NP}$ & $\mathrm{Neg}$ & $2+$ & $2+$ \\
\hline 3 & NP & Neg & $1+$ & $1+$ \\
\hline 4 & Lung metastasis & Neg & Neg & $1+$ \\
\hline 5 & Lung metastasis & $1+$ & $1+$ & Neg \\
\hline 6 & NP & Neg & Neg & $2+$ \\
\hline 7 & NP & $1+$ & Neg & $2+$ \\
\hline 8 & Nodal metastasis & $1+$ & $3+$ & Neg \\
\hline 9 & NP & Neg & Neg & $3+$ \\
\hline
\end{tabular}

$N P$ primary nasopharyngeal tumor

Neg negative staining

NA not available 


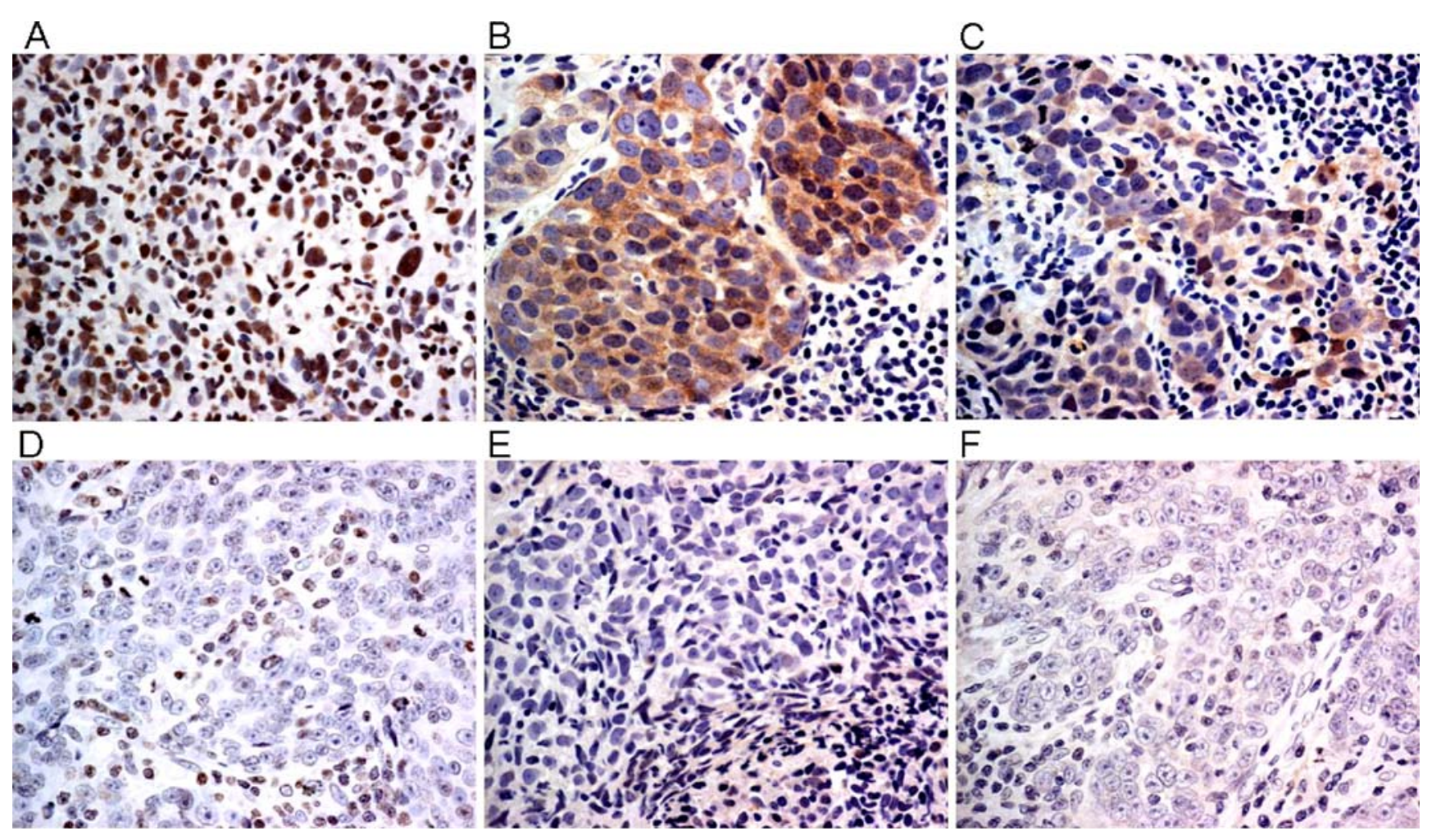

Fig. 5 Immunohistochemical staining for phosphorylated (p-) EGFR and p-AKT-ser473 in NPC samples. a \& d. Immunohistochemical, IHC. staining for EGFR-Tyr845. a Representative image showing strong nuclear (grade 3 ) positivity (case 10, original magnification, Mag. $\times 200$ ). d A case with negative staining (case 3, original mag. $\times$ 200). b \& e IHC staining for EGFR-Tyr992. b Representative image

tion may contribute to the enhanced sensitivity towards gefitinib in NPC [14]. This is supported by studies in lung cancer samples, where increased copy number of EGFR has been associated with better response to gefitinib [15].

Increased expression of EGFR-related ligands have been shown to predict resistance to EGFR TK inhibitors in vitro, these include overexpression of TGF- $\alpha$ in breast and pancreatic cancer cells $[16,17]$, and amphiregulin in breast and lung cancer cells $[16,18]$. In gefitinib-resistant breast cancer cells, exposure to gefitinib led to increased nucleocytoplasmic trafficking of EGFR ligands, thereby suggesting the presence of an intracrine feedback loop [16]. However, the current study did not identify any differences in expression of EGFR ligands between HK1 and HONE-1 cell lines, thus excluding the possibility that reduced basal activation of STAT3 and AKT in HK1 cells might be related to altered autocrine signaling in NPC.

Our in vitro data suggests that resistance to gefitinib may be associated with lower level of EGFR activation and persistent AKT activation in NPC cell lines, therefore we examined tumor samples obtained from gefitinib-resistant participants of a previously reported phase II study [5]. The study was terminated after 15 patients were entered because showing strong cytoplasmic (grade 3) positivity (case 9, original Mag. $\times 200$ ). e A case with negative staining (case 3, original mag. $\times$ 200). c \& f IHC staining for pAKT-ser473. c Representative image showing grade 1 positivity (case 9 , original mag. $\times 200$ ). $f$ A case with negative staining (case 5, original mag. $\times 200$ )

no clinical response was observed, hence the small number of biopsies obtained for the current study. Around 33\% (3/ 9 samples) of tumors weakly expressed p-AKT, which concurred with the reported $40 \%$ p-AKT overexpresssion rate in previous reports $[19,20]$. Over $50 \%$ (5/9 samples) of the current cohort showed no cytoplasmic EGFR expression, while over $60 \%$ expressed moderate to strong nuclear EGFR expression - the latter which is a negative prognostic factor in some cancers [21]. This was unexpected as our previous report found that over $80 \%$ of NPC overexpressed cytoplasmic EGFR [2]. However, the small number of tumor samples available makes it difficult to draw conclusions. The low level of AKT activation in NPC tumors from gefitinib-resistant patients is consistent with previous studies in lung cancer, where the lack of p-AKT expression was associated with poorer clinical outcome following gefitinib [12, 22].

In summary, a high level of basal EGFR activation (possibly from EGFR gene amplification) is an important indicator for sensitivity to gefitinib, while further studies are needed to confirm whether persistent AKT activation maybe associated with resistance. Tumoral status of EGFR activation and gene amplification should be further evalu- 
ated as biomarkers for selecting patients in clinical trials involving EGFR inhibitors.

Acknowledgements This study was supported by the Research Grant Council Competitive Earmarked Research Grant (Reference $4445 / 05 \mathrm{M})$. Result of this study was presented in part at the Annual Meeting of the American Association of Clinical Oncology 2007, abstract 3171, April 14-18, 2007, Los Angeles, CA. We thank Astra Zeneca Inc for providing gefitinib in this study.

\section{References}

1. Tao Q, Chan AT (2007) Nasopharyngeal carcinoma: molecular pathogenesis and therapeutic developments. Expert Rev Mol Med 9:1-24

2. Ma B, Poon T, To KF, Teo PML, Chan ML, Mo KF, Ma B, Lai MP, Ho S, Chan ATC (2003) Expression and prognostic significance of epidermal growth factor receptor and HER2 protein in nasopharyngeal carcinoma. Head Neck 25:864-872

3. Sung FL, Poon TC, Hui EP, Ma BB, Liong E, To KF, Huang DP, Chan AT (2005) Antitumor effect and enhancement of cytotoxic drug activity by cetuximab in nasopharyngeal carcinoma cells. In Vivo 19:237-245

4. Chan AT, Hsu MM, Goh BC, Hui EP, Liu TW, Millward MJ, Hong RL, Whang-Peng J, Ma BB, To KF, Mueser M, Amellal N, Lin X, Chang AY (2005) Multicenter, phase II study of cetuximab in combination with carboplatin in patients with recurrent or metastatic nasopharyngeal carcinoma. J Clin Oncol 23:3568-3576

5. Ma B, Hui EP, King A, To KF, Mo F, Leung SF, Kam M, Lo YM, Zee B, Mok T, Ahuja A, Chan AT (2008) A phase II study of gefitinib patients with metastatic or locoregionally recurrent nasopharyngeal carcinoma and evaluation of plasma EpsteinBarr virus DNA as a biomarker of efficacy. Cancer Chemother Pharmacol 62:59-64

6. Lui VW, Boehm AL, Koppikar P, Leeman RJ, Johnson D, Ogagan M, Childs E, Freilino M, Grandis JR (2007) Antiproliferative mechanisms of a transcription factor decoy targeting signal transducer and activator of transcription (STAT) 3: the role of STAT1. Mol Pharmacol 71:1435-1443

7. Seng TJ, Low JS, Li H, Cui Y, Goh HK, Wong ML, Srivastava G, Sidransky D, Califano J, Steenbergen RD, Rha SY, Tan J, Hsieh WS, Ambinder RF, Lin X, Chan AT, Tao Q (2007) The major $8 \mathrm{p} 22$ tumor suppressor DLC1 is frequently silenced by methylation in both endemic and sporadic nasopharyngeal, esophageal, and cervical carcinomas, and inhibits tumor cell colony formation. Oncogene 26:934-944

8. Adelaide J, Finetti P, Bekhouche I, Repellini L, Geneix J, Sircoulomb F, Charafe-Jauffret E, Cervera N, Desplans J, Parzy D, Schoenmakers E, Viens P, Jacquemier J, Birnbaum D, Bertucci F, Chaffanet M (2007) Integrated profiling of basal and luminal breast cancers. Cancer Res 67:11565-11575

9. Hopfner M, Sutter AP, Huether A, Schuppan D, Zeitz M, Scherubl H (2004) Targeting the epidermal growth factor receptor by gefitinib for treatment of hepatocellular carcinoma. J Hepatol 41:1008-1016

10. Bonaccorsi L, Carloni V, Muratori M, Formigli L, Zecchi S, Forti G, Baldi E (2004) EGF receptor (EGFR) signaling promoting invasion is disrupted in androgen-sensitive prostate cancer cells by an interaction between EGFR and androgen receptor (AR). Int J Cancer 112:78-86

11. Festuccia C, Gravina GL, Millimaggi D, Muzi P, Speca S, Ricevuto E, Vicentini C, Bologna M (2007) Uncoupling of the epidermal growth factor receptor from downstream signal transduction molecules guides the acquired resistance to gefitinib in prostate cancer cells. Oncol Rep 18:503-511

12. Han SW, Hwang PG, Chung DH, Kim DW, Im SA, Kim YT, Kim TY, Heo DS, Bang YJ, Kim NK (2005) Epidermal growth factor receptor (EGFR) downstream molecules as response predictive markers for gefitinib (Iressa, ZD1839) in chemotherapyresistant non-small cell lung cancer. Int J Cancer 113:109-115

13. Li B, Chang CM, Yuan M, McKenna WG, Shu HK (2003) Resistance to small molecule inhibitors of epidermal growth factor receptor in malignant gliomas. Cancer Res 63:7443-7450

14. Hui AB, Lo KW, Teo PM, To KF, Huang DP (2002) Genome wide detection of oncogene amplifications in nasopharyngeal carcinoma by array based comparative genomic hybridization. Int J Oncol 20:467-473

15. Takano T, Ohe Y, Sakamoto H, Tsuta K, Matsuno Y, Tateishi U, Yamamoto S, Nokihara H, Yamamoto N, Sekine I, Kunitoh H, Shibata T, Sakiyama T, Yoshida T, Tamura T (2005) Epidermal growth factor receptor gene mutations and increased copy numbers predict gefitinib sensitivity in patients with recurrent non-small-cell lung cancer. J Clin Oncol 23:6829-6837

16. Ferrer-Soler L, Vazquez-Martin A, Brunet J, Menendez JA, De Llorens R, Colomer R (2007) An update of the mechanisms of resistance to EGFR-tyrosine kinase inhibitors in breast cancer: Gefitinib (Iressa)-induced changes in the expression and nucleocytoplasmic trafficking of HER-ligands (Review). Int J Mol Med 20:3-10

17. Pino MS, Shrader M, Baker CH, Cognetti F, Xiong HQ, Abbruzzese JL, McConkey DJ (2006) Transforming growth factor alpha expression drives constitutive epidermal growth factor receptor pathway activation and sensitivity to gefitinib (Iressa) in human pancreatic cancer cell lines. Cancer Res 66:38023812

18. Kakiuchi S, Daigo Y, Ishikawa N, Furukawa C, Tsunoda T, Yano S, Nakagawa K, Tsuruo T, Kohno N, Fukuoka M, Sone S, Nakamura Y (2004) Prediction of sensitivity of advanced nonsmall cell lung cancers to gefitinib (Iressa, ZD1839). Hum Mol Genet 13:3029-3043

19. Yip WK, Leong VC, Abdullah MA, Yusoff S, Seow HF (2008) Overexpression of phospho-Akt correlates with phosphorylation of EGF receptor, FKHR and BAD in nasopharyngeal carcinoma. Oncol Rep 19:319-328

20. GM MJA, Pathmanathan R, Raab-Traub N (2004) Differential signaling pathways are activated in the Epstein-Barr virusassociated malignancies nasopharyngeal carcinoma and Hodgkin lymphoma. Cancer Res 64:5251-5260

21. MK LSY, Xia W, Matin A, Wen Y, Kwong KY, Bourguignon L, Hung MC (2001) Nuclear localization of EGF receptor and its potential new role as a transcription factor. Nat Cell Biol 3:802808

22. Cappuzzo F, Magrini E, Ceresoli GL, Bartolini S, Rossi E, Ludovini V, Gregorc V, Ligorio C, Cancellieri A, Damiani S, Spreafico A, Paties CT, Lombardo L, Calandri C, Bellezza G, Tonato M, Crino L (2004) Akt phosphorylation and gefitinib efficacy in patients with advanced non-small-cell lung cancer. J Natl Cancer Inst 96:1133-1141 